Чуев Константин Геннадьевич

аспирант кафедры социологии и управления Белгородского государственного

технологического университета им. В.Г. Шухова

\section{СОЦИАЛЬНАЯ КОМПЕТЕНТНОСТЬ РУКОВОДИТЕЛЯ В МАССОВОЙ И ЭКСПЕРТНОЙ ОЦЕНКАХ}

\section{Аннотация:}

В статье представлена комплексная характеристика социальной компетентности руководителей организации по результатам массового социологического и экспертного опросов. В рамках этой характеристики определено место социальной компетентности в деятельности руководителя, представлены мнения опрошенных о содержании социальной компетентности руководителя, результаты ее оценки и самооценки, приведены распространенные суждения руководителей о человеческой природе. Социальные факторы оцениваются в числе наиболее значимых для детерминации успешной деятельности руководителя и организации. В структуру социальной компетентности включены шесть ключевых компонентов: когнитивный (знания), практический (умения), инструментальный (навыки), мотивационный (мотивы), ценностный (ценности), персональный (личные качества). Руководители и эксперты придают сравнительно большее значение когнитивному и технологиче скому компонентам социальной компетентности. Сравнительно ниже оценивается ими значимость практического, персонального и особенно мотивационного и ценностного компонентов.

\section{Ключевые слова:}

социальная компетенция, социальная компетентность, социальные качества, организация, руководитель, управленческая деятельность, когни тивный компонент, технологический компонент, ценности, мотивы.

\section{Chuev Konstantin Gennadyevich}

PhD student Sociology and Management Department, Belgorod State Technological University

\section{SOCIAL COMPETENCE OF THE LEADER IN MASS AND EXPERT EVALUATION}

\section{Summary}

The study presents a comprehensive description of the social competence of the company's leaders based on the results of mass sociological and expert surveys. The research identifies the place of social competence in leader activities and presents the opinions of respondents on the content of the manager's social competence, the results of its evaluation and self-assessment. The common leaders' judgments on human nature are given. Social factors are evaluated as the most significant ones for determining the successful managerial activity. The structure of social competence includes six key components: cognitive (knowledge), practical (skills), instrumental (abilities), motivational (motives), value-based (values), personal (personal qualities). Leaders and experts mostly emphasize the cognitive and technological components of social competence. In their opinion, practical, personal and especially motivational and value-based components are much less significant.

Термин «социальная компетенция» и «социальная компетентность» все чаще используются в научных публикациях и на практике. Как утверждают исследователи, с 1980-х гг. наблюдается экспоненциальный рост исследований по данной проблематике [1]. Социальная компетентность играет основную роль там, где люди контактируют, взаимодействуют, сотрудничают. В сорере управленческой деятельности она решающим образом определяет успех руководителей. «Дефицит» социальной компетентности, проявляющийся в излишнем педантизме, неумении владеть собой, слабом контакте с людьми, завышенной требовательности к сотрудникам, переносе собственной эмоциональной неуравновешенности на окружающих, приводит к ошибкам и неудачам в управлении персоналом.

Недостаток социальной компетентности руководителя обусловлен несколькими факторами, в том числе когнитивным, т. е. пониманием/непониманием самого смысла социальной компетентности и, соответственно, адекватной/неадекватной его реализацией в управленческой практике. Предлагаемая статья как раз и посвящена доказательству данного тезиса. В качестве аргументов используются результаты авторского социологического исследования, проведенного на предприятиях ОАО «Холдинговая компания Энергомаш-Строй» (г. Белгород, опрошено 250 сотрудников предприятий, 29 руководителей структурных подразделений этих предприятий и 10 экспертов).

Компетентность руководителя в целом включает несколько составляющих ее элементов технологический, организационный и др. В ряду этих элементов находится и социальная компетентность, которая, по мнению экспертов и самих руководителей, участвующих в социологическом опросе, занимает в нем важное место (таблица 1). 
Таблица 1 - Оценка места социальной компетентности в деятельности руководителя, в \%

\begin{tabular}{|c|l|c|c|c|c|}
\hline \multirow{2}{*}{$\begin{array}{c}\text { No } \\
\mathbf{n}\end{array}$} & \multirow{2}{*}{ Шкала оценки } & \multicolumn{3}{|c|}{ Категория опрошенных } \\
\cline { 3 - 5 } & & \multicolumn{3}{|c|}{ Эксперты } \\
\cline { 3 - 5 } & & мужчины & женщины & все & 11,1 \\
\hline 1 & Центральное место & 28,6 & 0,0 & 20,7 & 88,9 \\
\hline 2 & Важное место & 61,9 & 75,0 & 65,5 & 0,0 \\
\hline 3 & Неважное место & 0,0 & 0,0 & 0,0 & 0,0 \\
\hline 4 & Затрудняюсь ответить & 4,8 & 0,0 & 3,4 & - \\
\hline 5 & Нет ответа & 4,8 & 25,0 & 10,3 & - \\
\hline
\end{tabular}

Заметим, что ни один из опрошенных не выбрал вариант ответа «неважное место». Напротив, подавляющее их большинство придает социальной компетентности «важное место», а некоторые - даже «центральное место». Вместе с тем если эксперты проявили максимальную чувствительность к статусу социальной компетентности, то среди руководителей оказалось немало затруднившихся с ответом (пункты 4 и 5 в таблице), что свидетельствует, скорее всего, о низком уровне осознания оцениваемого вида компетентности и, соответственно, его места в общем ряду «составляющих» компетентности руководителя.

Обращают на себя внимание также гендерные различия во мнениях относительно ценностного статуса социальной компетентности. Руководители-женщины, во-первых, проявили сравнительно более низкую чувствительность к статусу социальной компетентности (каждая четвертая из опрошенных ушла от ответа на поставленный вопрос); во-вторых, дали сравнительно более скромную оценку по сравнению с руководителями-мужчинами и экспертами. Эти различия наводят на мысль о том, что руководители-женщины сравнительно меньше, нежели мужчины, задумываются о степени важности социальной компетентности для руководителя, но это отнюдь не означает, что они менее социально компетентны, нежели мужчины, в своем поведении.

Реальное поведение руководителя с точки зрения его компетентности (социально-компетентное поведение) во многом зависит от того, какой смысл вкладывается в само понятие «социальная компетентность» (разумеется, при условии ее личностной идентификации). Формулируя релевантный вопрос социологической анкеты, мы исходили из того, что структура любой компетентности, в том числе и социальной, включает пять ключевых компонентов: знания, умения, навыки, мотивы, ценности (качества). В соответствии с этими элементами были сконструированы предложенные для респондентов и экспертов варианты ответов (таблица 2).

Таблица 2 - Мнения респондентов и экспертов о содержании социальной компетентности руководителя, в \%

\begin{tabular}{|c|c|c|c|c|c|}
\hline \multirow{3}{*}{$\begin{array}{l}\text { № } \\
\Pi / \Pi\end{array}$} & \multirow{3}{*}{ Вариант ответа } & \multicolumn{4}{|c|}{ Категория опрошенных } \\
\hline & & \multicolumn{3}{|c|}{ Руководители } & \multirow{2}{*}{ Эксперты } \\
\hline & & мужчины & женщины & Bce & \\
\hline 1 & $\begin{array}{l}\text { Знания о сотрудниках, их взаимоотношениях, мето- } \\
\text { дах управления людьми }\end{array}$ & 33,3 & 25,0 & 31,0 & 55,6 \\
\hline 2 & $\begin{array}{l}\text { Умение налаживать деловые отношения с сотрудни- } \\
\text { ками, осуществлять эффрективное управление ими }\end{array}$ & 23,8 & 25,0 & 24,1 & 22,2 \\
\hline 3 & $\begin{array}{l}\text { Владение навыками установления и поддержания } \\
\text { эффективных взаимоотношений (деловых и личных) } \\
\text { с сотрудниками }\end{array}$ & 23,8 & 50,0 & 31,0 & 33,3 \\
\hline 4 & $\begin{array}{l}\text { Стремление к установлению и поддержанию эффек- } \\
\text { тивных взаимоотношений }\end{array}$ & 9,5 & 0,0 & 6,9 & 11,1 \\
\hline 5 & $\begin{array}{l}\text { Обеспокоенность вопросами, относящимися не } \\
\text { только к производству, но и к подчиненным, их по- } \\
\text { требностям и интересам }\end{array}$ & 9,5 & 0,0 & 6,9 & 11,1 \\
\hline 6 & Наличие необходимых личных качеств & 4,8 & 0,0 & 3,4 & 22,2 \\
\hline
\end{tabular}

Прежде чем приступить к анализу табличных данных, следует принять во внимание одно важное обстоятельство. Социальная реальность, в которой осуществляется деятельность руководителя, многоаспектна, и все эти аспекты невозможно учесть в социологическом опросе. Поэтому мы пошли по пути поиска такого аспекта, который вобрал бы в себя содержательные особенности остальных аспектов и мог бы выполнить по отношению к ним презентационную функцию. В качестве такого аспекта были выбраны социальные отношения (взаимоотношения) в организации.

Теперь о самих табличных данных. Они, как видно, расходятся по отдельным категориям опрошенных. Эксперты придают сравнительно большее значение когнитивному («знания о...») и технологическому («иметь навыки...») компонентам социальной компетентности. Сравнительно ниже оценена ими значимость практического («умение налаживать...»), персонального («иметь личные каче- 
ства») и особенно мотивационного («иметь желание...») и ценностного («думать не только о производстве, но и...») компонентов. Аналогичный «расклад» мнений получился у самих руководителей (если рассматривать их безотносительно к гендерным различиям). При этом следует отметить тенденцию уменьшения сравнительной значимости мотивационного и ценностного компонентов.

Что касается межгендерных различий, то из общего массива мнений выделяются ответы руководителей-женщин. Во-первых, они придают сравнительно большее значение технологическому компоненту социальной компетентности («меньше рассуждать, а больше действовать»); во-вторых, они исключают из состава социальной компетентности три ее компонента - мотивационный, ценностный и персональный. Такая недооценка указанных компонентов может быть связана, на наш взгляд, с одним из трех возможных обстоятельств: 1) с довольно распространенным стереотипным толкованием компетентности, ограничивающим его знаниями, умениями и навыками («ЗУН») и принципиально не допускающим наличие иных содержательных компонентов; 2) с возможной «непривычностью» включения в структуру социальной компетентности мотивационного и ценностного компонентов; 3) с фрактическим «дефицитом» этих компонентов в социальном поведении руководителей-женщин и его самооправданием посредством принижения их сравнительной значимости.

Уяснение того, что опрашиваемые имеют определенное представление о содержании социальной компетентности, позволяет перейти к следующему вопросу, а именно к оценке и самооценке социальной компетентности руководителя (таблица 3).

Таблица 3 - Оценка и самооценка социальной компетентности руководителя, в \%

\begin{tabular}{|c|c|c|c|c|c|}
\hline \multirow{2}{*}{$\begin{array}{l}\text { № } \\
\Pi / \Pi\end{array}$} & \multirow{2}{*}{ Вариант ответа } & \multicolumn{3}{|c|}{ Категория опрошенных } & \multirow{2}{*}{$\begin{array}{c}\text { Самооценка } \\
\text { руководителя }\end{array}$} \\
\hline & & руководители & сотрудники & эксперты & \\
\hline 1 & Достаточно высоко & 34,5 & 14,0 & 22,2 & 24,1 \\
\hline 2 & Невысоко & 24,1 & 11,0 & 44,4 & 17,2 \\
\hline 3 & Низко & 3,4 & 18,9 & 0,0 & 0,0 \\
\hline 4 & По-разному & 34,5 & 27,4 & 33,3 & 27,6 \\
\hline 5 & Затрудняюсь ответить & 3,4 & 27,4 & 0,0 & 31,0 \\
\hline
\end{tabular}

Сначала обратимся к показателю чувствительности (восприимчивости) к предложенному вопросу, который, как и следовало ожидать, имеет максимальное значение у экспертов и почти максимальное значение $(0,97)$ у руководителей. Вместе с тем почти треть $(27,4 \%)$ опрошенных сотрудников затруднилась с оценкой социальной компетентности своих руководителей, что может быть связано или с недопониманием социальной компетентности, или с ее «выпадением» из рефлексивного пространства сотрудников. Что касается самого характера оценок, то они, как видно, заметно скромнее тех оценок, которые представили эксперты и руководители.

Следует отметить, что в ответах всех категорий опрошенных преобладает вариант «поразному», т. е. тот или иной уровень социальной компетентности руководителей - высокий, невысокий, низкий - проявляется по-разному в отдельных ситуациях, что зависит, можно предположить, от степени напряженности ситуации, согласованности действий, фактора неожиданности и многого другого.

Обратим внимание также на самооценку руководителей. Среди них нет никого, кто низко оценил бы уровень своей социальной компетентности, тогда как 18,9 \% сотрудников организации, находящихся в подчинении у опрашиваемых руководителей, дают оценку «низко».

Продолжая анализ социальной компетентности руководителя, можно предположить, что его социально-компетентное поведение зависит в значительной мере от того, какой смысл вкладывает он в «человеческую природу», с какими качествами идентифицирует человека.

В начале 1970-х гг. в Америке и Европе сформировались два основных направления в понимании миссии руководителя и стиля руководства [2, с. 43]. Теория «Х» исходила из того, что человек по своей природе ленив, не любит и не способен думать и обращаться с ним надо исключительно посредством манипулирования наказанием и поощрением. Вторая теория «У», развиваемая Д. Макгрегором, доказывала, что люди нацелены на получение позитивных результатов, которые мобилизуют их внутреннюю энергию, актуализируют заинтересованность в достижении высоких целей. Более того, правильное руководство побуждает их брать на себя ответственность. Радость успеха, признания окружающими оказывается даже более действенным фактором повышения их готовности трудиться, нежели рост зарплаты или денежные премии. Д. Макгрегором были представлены убедительные доводы для подтверждения тезиса о том, что действия руководителей обусловлены в значительной степени разделяемой ими концепцией человеческого поведения [3].

С учетом этого теоретического положения М.И. Дурыхиным были осуществлены интерпретация, измерение и оценка мотивационных установок руководителей структурных подразделений ООО «Холдинговая компания «Энергомаш-строй» (в исследовании приняли участие 200 ру- 
ководителей и 28 структурных подразделений) [4]. Им был составлен список из 16 суждений-индикаторов, выражающих склонность респондентов к теории «Х» или к теории «У». При этом были выделены 7 групп полярных критериев.

1. Отношение к труду: труд как естественная потребность - труд как внешняя необходи-

2. Степень ответственности: принятие дополнительной (сверхнормативной) ответственности - уклонение от ответственности.

3. Уровень профессионально-трудовых притязаний: стремление к реализации своих потенциальных возможностей - невысокий уровень притязаний и стремление к безопасности.

4. Побуждение к труду: внутренняя мотивация - принуждение.

5. Локус контроля: самоконтроль - внешний контроль.

6. Отношение к организации: отождествление с организацией - эгоцентризм и безразличие к организационным нуждам.

7. Отношение к переменам в организации: поддержка перемен в организации - сопротивление переменам в организации.

Нашим респондентам (руководителям структурных подразделений и сотрудникам), а также экспертам было предложено выразить свое согласие или несогласие с суждениями, выражающими их установки на человека как работника. В таблице 4 представлены данные об уровне согласия респондентов и экспертов с суждениями относительно человеческой природы.

Таблица 4 - Уровень согласия респондентов с суждениями о человеческой природе, в \%

\begin{tabular}{|l|c|c|}
\hline \multicolumn{1}{|c|}{ Суждение о человеческой природе } & Руководители & Сотрудники \\
\hline $\begin{array}{l}\text { 1. Большинство людей отрицательно относится к труду и всеми силами } \\
\text { старается «увильнуть от необходимости работать }\end{array}$ & 67,1 & 11,1 \\
\hline 2. Труд так же естествен для человека, как игра или отдых & 45,1 & 100,0 \\
\hline $\begin{array}{l}\text { 3. Человек не является прирожденным лентяем. Его отрицательное отно- } \\
\text { шение к труду - результат приобретенного опыта }\end{array}$ & 48,8 & 77,8 \\
\hline 4. Люди стремятся уклониться от ответственности & 34,8 & 66,7 \\
\hline 5. Люди не амбициозны и нуждаются прежде всего в безопасности & 46,3 & 22,2 \\
\hline $\begin{array}{l}\text { 6. Заложенный в человеке потенциал позволяет людям в надлежащих } \\
\text { условиях не только принимать на себя, но и искать дополнительную ответ- } \\
\text { ственность }\end{array}$ & 56,1 & 88,9 \\
\hline $\begin{array}{l}\text { 7. Люди обладают воображением, избирательностью и творческими спо- } \\
\text { собностями, которые могут быть использованы в трудовом процессе }\end{array}$ & 57,9 & 100,0 \\
\hline $\begin{array}{l}\text { 8. Участие людей в процессе труда осуществляется только под принужде- } \\
\text { нием, под контролем }\end{array}$ & 40,9 & 22,2 \\
\hline $\begin{array}{l}\text { 9. Решая поставленные задачи, работники могут самостоятельно регули- } \\
\text { ровать свою деятельность и контролировать трудовой процесс }\end{array}$ & 59,1 & 88,9 \\
\hline 10. Люди эгоцентричны и безразличны к нуждам организации (предприятия) & 45,7 & 33,3 \\
\hline 11. Люди отождествляют себя с организацией и дорожат ее честью & 50,6 & 66,7 \\
\hline 12. Люди сопротивляются переменам в организации & 41,5 & 66,7 \\
\hline 13. В надлежащих условиях люди поддерживают перемены в организации & 53,0 & 88,9 \\
\hline 14. Люди стремятся к реализации своих потенциальных возможностей & 53,0 & 88,9 \\
\hline $\begin{array}{l}\text { 15. Задача руководства состоит в принуждении к труду и контроле за дей- } \\
\text { ствиями работников }\end{array}$ & 43,3 & 33,3 \\
\hline $\begin{array}{l}\text { 16. Задача руководства заключается в развитии потенциальных способно- } \\
\text { стей работников и в оказании им помощи в их применении для решения } \\
\text { общих задач }\end{array}$ & 57,3 & 100,0 \\
\hline
\end{tabular}

Как это ни парадоксально, эксперты (как и руководители) придерживаются в большей мере положительного мнения о человеческой природе, нежели рядовые сотрудники организации. Позитивного мнения о социальных качествах человека придерживаются 88,9\% руководителей и $53,3 \%$ рядовых сотрудников, негативного - 36,5 и 45,6 \% соответственно. Вместе с тем отдельные качества «человеческой природы» руководители оценивают ниже, нежели рядовые сотрудники. В разряд этих качеств попали «ответственность», «идентификация с организацией», «инновационное поведение». Сотрудникам организации не хватает, по мнению их руководителей, прежде всего корпоративной ответственности, инновационности и корпоративной идентичности. Все это может свидетельствовать о «пробелах» в корпоративной культуре организации и необходимости ее повышения.

Социальная компетентность руководителя проявляется при решении соответствующих социальных - вопросов. В связи с этим выяснялось мнение руководителей о сравнительной важности этих вопросов, как, впрочем, и других (таблица 5). 
Таблица 5 - Оценка сравнительной важности вопросов, решаемых руководителем, в баллах

\begin{tabular}{|c|c|c|c|c|}
\hline \multirow{2}{*}{$\begin{array}{l}\text { № } \\
\text { ח/ח }\end{array}$} & \multirow{2}{*}{ Категория вопросов } & \multicolumn{3}{|c|}{ Категория опрошенных } \\
\hline & & мужчины & женщины & Bce \\
\hline 1 & Производственные & 4,0 & 4,3 & 4,1 \\
\hline 2 & Экономические & 4,1 & 4,3 & 4,1 \\
\hline 3 & Финансовые & 4,1 & 4,1 & 4,1 \\
\hline 4 & Социальные & 3,6 & 4,1 & 3,8 \\
\hline 5 & Организационные & 3,7 & 3,8 & 3,7 \\
\hline 6 & Хозяйственные & 3,6 & 5,0 & 3,7 \\
\hline 7 & Связи с общественностью & 3,6 & 3,4 & 3,5 \\
\hline
\end{tabular}

Социальные вопросы занимают, как видно, серединное положение с оценочным баллом 3,8, уступая производственным, экономическим и финансовым, но опережая по значимости организационные, хозяйственные и PR-вопросы. При этом руководители-женщины придают решению социальных вопросов сравнительно большее значение, нежели руководители-мужчины.

Внимание к социальной компетентности руководителя, оценке ее фактического уровня и способов повышения связано не столько с личными предпочтениями исследователя, сколько с объективными обстоятельствами, а именно с явным или неявным действием в организации социальных факторов и их значимой ролью в детерминации успешности ее деятельности (таблица 6).

\section{Таблица 6 - Сравнительная оценка действенности групп значимых фракторов} (максимальное значение - 5 баллов)

\begin{tabular}{|c|l|c|c|c|}
\hline \multirow{2}{*}{$\begin{array}{c}\text { № } \\
\mathbf{n}\end{array}$} & \multicolumn{1}{|c|}{ Группа факторов } & \multicolumn{3}{|c|}{ Категории опрошенных } \\
\cline { 3 - 5 } & & мужчины & женщины & все \\
\hline 1 & Производственные & 3,9 & 3,9 & 3,9 \\
\hline 2 & Экономические & 3,8 & 3,6 & 3,7 \\
\hline 3 & Финансовые & 4,0 & 4,0 & 4,0 \\
\hline 4 & Социальные & 4,0 & 3,5 & 4,0 \\
\hline 5 & Организационные & 4,0 & 3,5 & 3,8 \\
\hline 6 & Хозяйственные & 3,9 & 3,3 & 3,7 \\
\hline 7 & Связи с общественностью & 3,9 & 3,1 & 3,7 \\
\hline
\end{tabular}

Социальные факторы, как видно, входят в группу наиболее значимых факторов, наряду с финансовыми, в детерминации успешной деятельности организации. Это воздает должное высокой значимости данной группы фракторов, но вместе с тем акцентирует задачу их целенаправленного - рационального и эффективного использования. В связи с этим руководителям было предложено поделиться мнениями о том, в какой мере им удается использовать социальные факторы эффективности производства, наряду, разумеется, с другими фракторами (таблица 7).

Таблица 7 - Распределение ответов руководителей на вопрос: «В какой мере Вам удается учитывать и использовать следующие фракторы эффективности производства? Оценка по 5-балльной шкале: 5 - хорошо удается... 1 - совсем не удается»

\begin{tabular}{|c|l|c|c|c|}
\hline \multicolumn{1}{|c|}{$\begin{array}{c}\text { № } \\
\mathbf{n} / \mathbf{n}\end{array}$} & \multicolumn{1}{|c|}{ Группа факторов } & \multicolumn{3}{|c|}{ Категория опрошенных } \\
\cline { 3 - 5 } & & мужчины & женщины & общее \\
\hline 1 & Производственные & 3,6 & 3,1 & 3,5 \\
\hline 2 & Экономические & 3,8 & 3,5 & 3,7 \\
\hline 3 & Финансовые & 4,0 & 3,5 & 3,8 \\
\hline 5 & Социальные & 3,9 & 3,4 & 3,8 \\
\hline 6 & Организационные & 3,8 & 3,1 & 3,6 \\
\hline 7 & Хозяйственные & 3,8 & 3,1 & 3,6 \\
\hline
\end{tabular}

Как видно из табличных данных, по всем группам факторов примерно в равной мере чтото удается учитывать и использовать, а что-то нет. Социальные фракторы, наряду с финансовыми, находятся здесь в сравнительно более предпочтительном положении. Обращает на себя внимание то, что руководители-женщины более критичны в оценке результативности и эффективности целенаправленного использования социальных факторов в управленческой практике.

Таким образом, большинство опрошенных руководителей, сотрудников и экспертов придают важное значение социальной компетентности. При этом само социально-компетентное поведение зависит от того, какой смысл вкладывается в понятие «социальная компетентность». Руководители и эксперты придают сравнительно большее значение когнитивному и технологическому компонентам социальной компетентности. Сравнительно ниже оценивается ими значимость практического, 
персонального и особенно мотивационного и ценностного компонентов. Социально-компетентное поведение руководителя зависит также от того, какой смысл вкладывает он в «человеческую природу». Подавляющее большинство руководителей придерживаются положительного мнения о социальных качествах человека и, соответственно, ориентируются на это в своей практической деятельности. Решаемые ими социальные вопросы занимают серединное положение, уступая производственным, экономическим и финансовым, но опережая по значимости организационные, хозяйственные и PR-вопросы. Социальные фракторы оцениваются в числе наиболее значимых для детерминации успешной деятельности руководителя и организации.

\section{Ссылки:}

1. Вундерер Р., Дик П. Ключевая роль социальной компетенции в концепции сопредпринимательства // Менеджмент и маркетинг. 2003. № 5. С. 105-110.

2. Зигерт В., Ланг Л. Руководить без конфликтов. М., 1990. С. 42-43.

3. MacGregor D. The human side of enterprise. N. Y., 1960.

4. Дурыхин М.И. Традиции и инновации в управлении процессами трудовой мотивации : дис. ... канд. социол. наук. М., 2006. C. $66-70$

\section{References:}

Durykhin, Ml 2006, Traditions and innovations in the management of labor motivation processes, PhD thesis, Moscow, pp. 66-70, (in Russian).

MacGregor, D 1960, The human side of enterprise, New York.

Wunderer, R \& Dick, P 2003, 'The key role of social competence in the concept of co-entrepreneurship', Menedzhment $i$ marketing, no. 5, pp. 105-110, (in Russian).

Zigert, V \& Lang, L 1990, Lead without conflict, Moscow, pp. 42-43, (in Russian). 